\title{
Dexmedetomidine versus Propofol Sedation for Prevention of Postoperative Delirium: Clarifications Required [Letter]
}

\section{Jiawen Deng (D)}

Kiyan Heybati ${ }^{2}$

'Faculty of Health Sciences, McMaster University, Hamilton, Ontario, Canada; ${ }^{2}$ Mayo Clinic Alix School of Medicine, Mayo Clinic, Rochester, MN, USA
Correspondence: Jiawen Deng Faculty of Health Sciences, McMaster University, 1280 Main Street West, Hamilton, ON, L8S 4L8, Canada

Tel + | 613618-9734

Fax + I 905525-9140

Email dengj35@mcmaster.ca

Kiyan Heybati

Mayo Clinic Alix School of Medicine, 200

Ist St SW, Rochester, MN, 55905, USA

Tel + I 507266-5568

$\mathrm{Fax}+\mid$ 905525-9|40

Email heybatik@mcmaster.ca

\section{Dear editor}

We read with great interest the randomized controlled trial (RCT) published by Shi et $\mathrm{al}^{1}$ which investigated the efficacy of dexmedetomidine in reducing the incidence and duration of postoperative delirium in older adults following cardiac surgery. While the results provided valuable insights, several clarifications are required in regards to the trial's methodology and conduct.

Firstly, the authors claimed that their RCT was registered in the Chinese Clinical Trial Registry (ChiCTR No. ChiCTR-IOR-17014122). However, the clinical trial associated with this registration number compared the efficacy of dexmedetomidine as an adjuvant therapy to ropivacaine in patients undergoing laparoscopic colon operations, ${ }^{2}$ which is drastically different from the published RCT. Furthermore, we were unable to identify any registration associated with this trial following searches on ChiCTR using the authors' affiliations. Prospective registration of clinical trials is crucial for ensuring scientific transparency and integrity, and is an essential component of the CONSORT statement. ${ }^{3}$ Therefore, it is concerning that the authors reported an invalid registration number as it is unknown whether this RCT was prospectively registered.

Moreover, it is unclear whether dexmedetomidine was used as an adjunctive therapy to propofol or a monotherapy. In the Results section, the authors referred to the experimental and control groups as "DEX" and "PRO", respectively. This implies that the RCT compared dexmedetomidine monotherapy against propofol monotherapy. However, the authors also claimed that both groups received propofol for general anesthesia and postoperative sedation in their methodology, which conflicts with the implications of the groups' naming schemes. Additionally, the authors did not clarify whether the dexmedetomidine regimen was continued upon ICU admission and only commented on the propofol regimens. The authors' discussion further complicated this as they concluded that dexmedetomidine might be both an "attractive adjuvant," as well as an "alternative" to propofol. This could suggest that their trial involved both dexmedetomidine adjuvants and monotherapy. We could not verify the exact intervention arms involved in this trial, as a valid trial registration number was not provided.

This unclear reporting may lead to errors in future reviews and treatment guidelines. For instance, this RCT was included in a recent meta-analysis by Abowali et al which investigated the efficacy of dexmedetomidine compared to 
propofol monotherapy for postoperative sedation. ${ }^{4}$ Abowali et al concluded that dexmedetomidine could not reduce delirium incidence compared to propofol due to the inclusion of this RCT. A letter ${ }^{5}$ in reply to the metaanalysis, noted that the inclusion of this RCT may have been erroneous, shifting the treatment effect towards null.

We believe that dexmedetomidine may have been administered as an adjuvant to propofol as the authors' conclusion contradicts the findings of previous RCTs in regards to postoperative delirium, which generally found dexmedetomidine monotherapy to be superior in reducing postoperative delirium incidence compared to propofol. ${ }^{4}$ This may be due to propofol shifting the treatment effect of dexmedetomidine as it serves as a sedative-hypnotic agent. These concerns would need to be addressed by the authors to clarify the exact regimens utilized in this RCT.

\section{Disclosure}

The authors declare no competing interests in this communication.

\section{References}

1. Shi C, Jin J, Qiao L, Li T, Ma J, Ma Z. Effect of perioperative administration of dexmedetomidine on delirium after cardiac surgery in elderly patients: a double-blinded, multi-center, randomized study. Clin Interv Aging. 2019;14:571-575. doi:10.2147/CIA.S194476

2. Jiang MR, Ma JH. Dexmedetomidine added to ropivacaine in ultrasound-guided tranversus abdominis plane block improved postoperative analgesia and recovery after laparoscopic radical operation on colon. Chinese Clinical Trial Registry; December 24, 2017. Available from: http://www.chictr.org.cn/showproj.aspx?proj=24187. Accessed July 3, 2021.

3. Schulz KF, Altman DG, Moher D; CONSORT Group. CONSORT 2010 statement: updated guidelines for reporting parallel group randomised trials. BMJ. 2010;340:c332. doi:10.1136/bmj.c332

4. Abowali HA, Paganini M, Enten G, Elbadawi A, Camporesi EM. Critical review and meta-analysis of postoperative sedation after adult cardiac surgery: dexmedetomidine versus propofol. J Cardiothorac Vasc Anesth. 2021;35(4):1134-1142. doi:10.1053/j. jvca.2020.10.022

5. Heybati K, Deng J, Zhou F, Ali S. Current evidence demonstrates a significant reduction in the incidence of delirium with post-operative dexmedetomidine versus propofol sedation. $J$ Cardiothorac Vasc Anesth. 2021. doi:10.1053/j.jvca.2021.06.026

\footnotetext{
Dove Medical Press encourages responsible, free and frank academic debate. The content of the Clinical Interventions in Aging 'letters to the editor' section does not necessarily represent the views of Dove Medical Press, its officers, agents, employees, related entities or the Clinical Interventions in Aging editors. While all reasonable steps have been taken to confirm the content of each letter, Dove Medical Press accepts no liability in respect of the content of any letter, nor is it responsible for the content and accuracy of any letter to the editor.
}

Clinical Interventions in Aging

\section{Publish your work in this journal}

Clinical Interventions in Aging is an international, peer-reviewed journal focusing on evidence-based reports on the value or lack thereof of treatments intended to prevent or delay the onset of maladaptive correlates of aging in human beings. This journal is indexed on PubMed Central, MedLine, CAS, Scopus and the Elsevier
Bibliographic databases. The manuscript management system is completely online and includes a very quick and fair peer-review system, which is all easy to use. Visit http://www.dovepress.com/ testimonials.php to read real quotes from published authors. 